\title{
The Power of Partners: A Qualitative Study of the Dissonance between African-American Females' Interest in Practicing Secondary Abstinence and Continued Sexual Activity
}

\author{
Erin L. P. Bradley ${ }^{1}$, Kirk W. Elifson' ${ }^{1}$ Jessica M. Sales ${ }^{1}$, Ralph J. DiClemente ${ }^{1,2}$ \\ ${ }^{1}$ Department of Behavioral Sciences and Health Education, Emory University Rollins School of Public Health, \\ Atlanta, USA \\ ${ }^{2}$ Department of Pediatrics, Division of Infectious Diseases, Epidemiology, and Immunology Emory University \\ School of Medicine, Atlanta, USA \\ Email: ebrad12@emory.edu
}

Received 26 April 2014; revised 9 June 2014; accepted 25 June 2014

Copyright (C) 2014 by authors and Scientific Research Publishing Inc. This work is licensed under the Creative Commons Attribution International License (CC BY). http://creativecommons.org/licenses/by/4.0/

(c) (7) Open Access

\begin{abstract}
Reducing disparities in STI/HIV rates for young heterosexual African-American women in the US is a public health priority. Although several strategies can reduce risk, some sexually experienced young women are choosing to abstain from sex for various reasons and periods of time following sexual debut, a practice known as secondary abstinence. However, others who desire to practice secondary abstinence find it difficult to do so. This qualitative study explored barriers that explained the dissonance between interest in secondary abstinence and continued sexual activity. In-depth interviews were conducted with 20 sexually-experienced African-American adolescent females, ages 18 - 23, who expressed interest in secondary abstinence. Partner-related barriers that created power imbalances presented the greatest challenges to becoming or remaining abstinent. Findings suggest that teaching young women how to recognize characteristics of healthy and unhealthy relationships, identify power imbalances, communicate assertively and develop positive coping skills can empower young women to build healthier relationships with their partners.
\end{abstract}

\section{Keywords}

Sexual Behavior, African-American Females, Qualitative Methods, STI/HIV Prevention, Partner Influence 


\section{Introduction}

Disparities in rates of HIV/AIDS and STIs in the US are striking. AIDS diagnoses rates were 20 times higher for African-American women compared to White women in 2010 [1]. Additionally, young African-American women lead in gonorrhea and chlamydial infections [2]. A number of effective risk reduction interventions have been shown to reduce risky sexual behaviors, such as unprotected vaginal sex, and STI rates among participants [3]. Several that were designed specifically to address the needs of this population, including SISTA [4], SiLHE [5], HORIZONS [6], Enhanced Negotiation [7], and Sister to Sister [8], among others, are now endorsed by the Centers for Disease Control and Prevention as effective, evidence-based interventions and widely disseminated in the US [9]. While advances in the development and dissemination of such programs are promising, researchers continue to devote attention to identifying factors that may prevent individuals from successfully implementing risk reduction strategies taught in these interventions.

One area that has garnered attention is one's relationship with an intimate partner. Previous research has highlighted the importance of considering the context in which sexual decision-making and behavior take place to provide a more complete picture [10]-[12]. For example, research on risky sexual behaviors has shown that a partner's disapproval of condoms contributes to nonuse of condoms among African-American females [13]-[15]. Recent qualitative studies of condom use among heterosexual African-American males highlighted beliefs that condoms interfere with sexual pleasure [16] and are associated with infidelity or mistrust, making them suitable for use primarily with new or casual partners [16] [17]. Consequently, for young women who become educated about the dangers of unprotected sex, proposing condom use may cause conflict in their relationships. Therefore, some young women may be unable to translate prevention knowledge into behavior change.

Similarly, some sexually experienced young women choose to refrain from sexual activity after sexual debut, a practice known as secondary abstinence. Periods of abstinence are significant because they eliminate opportunities for exposure to STIs as well as HIV acquired through sex. However, some motivated to abstain may experience challenges that make it difficult or impossible to do so. Data from a clinic-based sample of sexually experienced African-American adolescent females participating in a risk reduction intervention suggests all who are motivated to abstain may not be equipped to do so. Although 21 percent of participants reported being very interested in becoming abstinent at baseline assessment, only 7 percent of this group had not engaged in vaginal sex between baseline and 6-month assessment [18]. In comparison to condom use, much less research attention has been devoted to understanding what factors contribute to dissonance between interest in and the practice of secondary abstinence. One study of college students identified barriers such as alcohol use, physical attraction, and involvement in a serious relationship [19]. A qualitative study of African-American adolescent females revealed pressure from romantic partners made abstinence a challenge [20]. Findings from these studies, similar to those on condom use, indicate the role of partner influence warrants further investigation.

To our knowledge there have been no published studies in the literature examining dissonance between interest in secondary abstinence and continued sexual activity among African-American young women at risk for STI/HIV. Yet abstinence is a valuable strategy that is included in many comprehensive approaches since infection risk is reduced, at least temporarily, during periods of sexual inactivity. Thus, gaining insight about AfricanAmerican females' experiences with secondary abstinence may prove useful for creating new and strengthening existing interventions that adequately equip them to overcome barriers and cultivate relationships that are supportive of their sexual health choices. Since little is known in this area, a qualitative approach was employed to gain an in-depth understanding of their experiences. Therefore, the purpose of this qualitative study was to identify barriers that may prevent sexually experienced African-American young women who are interested in practicing secondary abstinence from doing so.

\section{Methods}

\subsection{Study Design}

For the purposes of this study, the researchers employed a qualitative approach. Grounded theory, an inductive approach consisting of systematic data collection and analysis techniques, was utilized to allow the barriers to originate from the data instead of being determined a priori [21] [22]. Data collection and analysis is an iterative process. Figure 1 outlines the research process. 


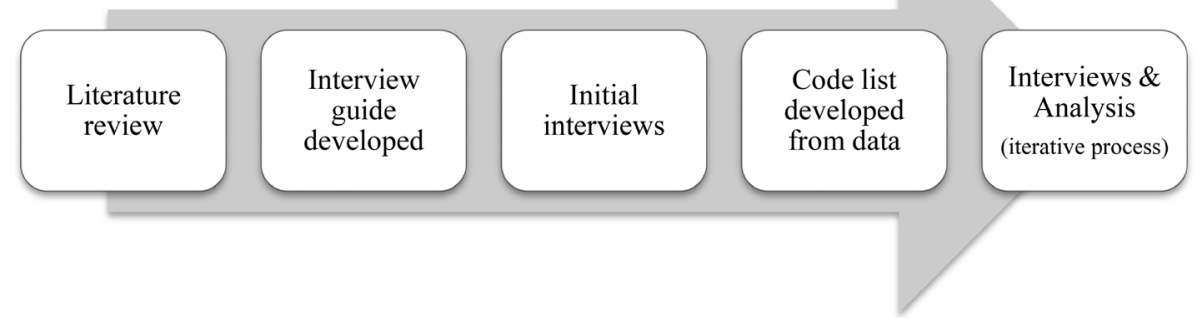

Figure 1. Research process.

\subsection{Participants}

Participants were 20 sexually experienced African-American females ages 18 to 23 who completed a 36-month HIV-risk reduction intervention study (Table 1). The median age of the participants in this study was 20.5 years. Eight participants were high school students. Twelve had completed high school, six of whom were in college. Nine young women were mothers; most $(n=7)$ had only one child. The mean age of initiation of sex was 15.3 years $(S D=1.87)$.

Eleven participants self-identified as secondary abstainers. Length of abstinence at the time of the interview ranged from approximately four weeks to one year. Thirteen young women, six of whom were secondary abstainers, had boyfriends. Two were in a romantic relationship with a male they did not formally classify as a boyfriend. One had only a casual sexual partner with whom she was not involved romantically. Four were not in a relationship at the time of the interview. Six of nine young women who remained sexually active (75\%) believed abstinence may negatively impact her relationship.

\subsection{Recruitment}

Participants were invited to be screened for eligibility after their final intervention study assessment. Purposive sampling ensured only young women with interest in practicing abstinence were interviewed. They were asked to classify themselves as very, somewhat, or not at all interested in abstaining. Since dissonance between interest in and practice of abstinence was under investigation, those who indicated no interest in abstinence were not eligible to participate. Respondents provided written consent prior to their interview and received \$25 compensation for their time. Study procedures were approved by Emory University's IRB.

\subsection{Data Collection \& Analysis}

A semi-structured interview format was used to ask respondents a series of open-ended questions about their experiences with sex and abstinence. Interviews were approximately one hour and were audio-recorded, transcribed verbatim and checked for accuracy. Interviews continued until theoretical saturation was reached, resulting in a final sample size of 20.

Coding was guided by an approach that included open, axial, and selective coding [22]. Open coding consisted of a line-by-line examination of each transcript to increase confidence that the codes were grounded in the interview data. Transcripts were read again and frequently occurring codes used to code larger segments of text. Categories, such as relationship barriers, and subcategories, such as power imbalance were developed during this process. Relationships between categories and subcategories were identified and refined through axial and selective coding. For example, analysis revealed ways that refusing sexual advances could be impacted by a young woman's sexual decision-making power, which may vary based on financial dependence on her partner for instance. To assess the trustworthiness of the coding, the PI developed a code list from the first six transcripts and interviewer notes. A second researcher independently coded the same six transcripts and compared code lists with the PI. The discussion resulted in the creation of a separate code to capture sexual situations as a barrier. The revised list was used to code subsequent interview transcripts. Revisions made during remainder of the data collection and analysis process were minimal. Memoing was also utilized in each stage of coding to highlight significant codes and key issues for further exploration. Advanced memos, which are more analytic 
Table 1. Demographic characteristics.

$\begin{array}{cc}\text { Age (yrs) } & 20.5 \\ \text { Education (n) } & \\ \text { High school } & 8 \\ \text { Completed high school, no college } & 6 \\ \text { Attending college } & 6 \\ \text { Number of children (n) } & \\ 0 & 11 \\ 1 & 7 \\ 2+ & 2 \\ \text { Abstinent at time of interview (n) } & \\ \text { Yes } & 11 \\ \text { No } & 9 \\ \text { Partner type (n) } & \\ \text { Boyfriend } & 13 \\ \text { Casual partner } & 2 \\ \text { None } & 4\end{array}$

and permit comparisons between categories or concepts, respondents, or study findings and the literature for instance [23], were also developed during axial and selective coding. These memos expounded on proposed relationships between categories recorded in early memos or discovered later in the coding process.

\section{Results}

Although young women noted a few intrapersonal barriers, such as sexual thoughts, as barriers to practicing secondary abstinence, barriers that arose from past and current relationships were most salient. Partner-related barriers contributed to power imbalances that favored the male and made it extremely difficult or impossible to act on the desire to abstain (Table 2). The context of interactions with one's partner created challenges as well. Each is described, in turn, below.

\subsection{Negative Response from Partner}

The majority of participants experienced or anticipated negative responses from their partners. There was a prevailing belief among respondents that most men would not be interested in abstinence. Several young women expressed strong beliefs that sex was a priority for males, making comments such as, "All a man want is sex" and "Every guy that I encountered have sex on their mind....That's just a guy. In fact, sex is gonna be on their mind when they born 'till they die." Nearly half believed a man may have sex with someone else if the woman he had a relationship with was abstinent. A remark by a 21-year-old woman who continued a sexual relationship with a casual partner conveyed this sentiment: “It's just the simple fact that sex plays a big part in a man's life. And it's like if you're not giving it to him he will find it somewhere else."

Most young women who told a current or past partner about their desire to abstain said he did not respond positively. For example, a 22-year-old college student who had two previous year-long stints of abstinence recalled a conversation with her boyfriend:

I told him that I was thinking about not having sex for a while, and of course, as a dude that's sexually active, he's like, "You can't be serious. Really?" and I'm like, "Yeah. I just want to try it out”....He was like, "Are you serious? That is so rude. Why would you do that to me?”

Another 18-year-old woman who had been in a relationship with her partner off-and-on for several years also recalled her partner's negative response to ceasing sex:

I said to him, "What if we couldn't have sex no more? Would you still be with me?" And he told me "No", 'cause I couldn't have sex no more....It upset me a lot, because it's not always about sex in a relationship. 
Table 2. Summary of partner-related barriers to secondary abstinence.

\begin{tabular}{cr}
\hline \multicolumn{1}{c}{ Barrier } & Brief description \\
\hline $\begin{array}{c}\text { Negative partner response } \\
\text { Financial dependence }\end{array}$ & Experienced or anticipated negative reaction that may result in loss of the relationship \\
Inaccurate perception of power & Financial dependence that may create sexual obligation \\
Sexual situations & Unaware of power imbalance favoring male partner \\
Time spent alone with a partner and/or inability to establish and enforce \\
boundaries that prevent progression to sex when alone with partner
\end{tabular}

While current secondary abstainers recalled both supportive and unsupportive responses, none of the young women who remained sexually active discussed an experience where their partner responded positively to abstinence.

A young woman's belief about her partner's response can be critical. If choosing abstinence may jeopardize her relationship, a young woman invested in her relationship may continue having sex even after she no longer wants to do so. Although most respondents did not directly identify concern for partner loss as a barrier, perhaps because of the disempowering nature of the predicament, three young women spoke openly about continuing sex in order to keep a partner.

Further, a few young women $(n=4)$ were less confident about refusing sex with partners with whom they had previously had sex. Some partners may attempt to convince the young woman that it is unfair to alter that dimension of their relationship. A 21-year-old woman struggled with pressure to continue sex after she recently succumbed to sexual pressure after abstaining for a year:

I feel like for us to have already done it and for me to say, "Um, you know what? I don't want to have sex anymore".... It's like, “Okay your belief was that this amount of months ago, so why does it change now?" Kind of like, we had sex once, why would we go to be abstinent?

In sum, if a young woman felt pressure to continue having sex out of obligation or fear that she may lose her relationship then practicing abstinence seemed daunting. Thus, removing such barriers may increase the likelihood of successful attempts to abstain.

\subsection{Financial Dependence}

Six respondents discussed relationships where they felt a sense of sexual obligation to a current or past partner because of his financial support, two of whom were very interested in becoming abstinent but unable to do so because of their financial dependence. For example, a 21-year-old woman discussed her inability to end her relationship with a married man upon whom she depended financially:

... I want to be abstinent. But I'm just like, I got so much going on, and I need so much at this time and he really helps me out. I don't think that I could just tell him “No” right now.

Financial dependence can create an unhealthy dynamic within a relationship in which a woman who does not desire sexual involvement with a certain man is participating in sex in exchange for financial support.

\subsection{Inaccurate Perception of Power}

It is important to note that most respondents believed they primarily controlled or had equal power in sexual decision-making. Only two young women interested in becoming abstinent but still sexually active spoke about their respective partner's control over sexual decision-making. One who had abstained twice before for approximately a year each time, but encountered many challenges with her current partner, shared her frustration with the power imbalance:

He's one of them guys where he's, like, domineering...when we talking about sex it's like we don't really talk about it. It's like either I say we're not doing it and then he's like, “OK, whatever.” Then it happens. It's like he has more control of me-not me but the situation—and I hate that.

However, many of the respondents were unaware that power imbalances that favored their partners existed in their relationships. For example, respondents discussed their concern about a negative response from their partner, but did not make the connection between fear of losing their relationship and their decision to continue having sex despite wanting to abstain. 


\subsection{Sexual Situations}

Young women also believed being in sexual situations posed a significant threat to practicing secondary abstinence and repeatedly spoke about the importance of avoiding situations or establishing boundaries within situations. Three young women discussed how living with (co-habitating) or in close proximity to a partner (i.e. coed dormitory) complicated efforts to abstain by creating regular opportunities for sex. Seventeen respondents discussed risks associated with spending time alone with males in private settings. For example, pressure from a partner was typically applied in the context of a private situation versus with a group of people or in a public place. As a 23-year-old college student abstinent for four months in a new relationship said, "... I just try to avoid the alone times because if we're together in an alone setting then it's going to be pressured more." Consequently, as opportunities for temptation created by these "alone times" increase, opportunities for refusal failures increase as well.

Moreover, sexual situations altered the power of intrapersonal barriers. For example, several young women said that although they may desire sex they are able to deal with sexual thoughts or feelings by doing something else to divert their minds from sex. However, in a sexual situation the threat of a manageable, internal obstacle such as sexual desire was heightened when combined with sexual pressure from her partner. One respondent discussed how combating sexual urges became much more difficult when she found herself in sexual situations with the father of her child: "He'll kiss on me and stuff like that, and then it makes you weak. So when you weak you just fall into having sex."

Six young women described protective strategies such as not spending time at home or going out with other people or couples for example. Others explained that implementing boundaries, such as not limiting the progression of sex-related activities beyond a certain point when they are unable to avoid situations with sexual possibility or choose not to do so. For example, one young woman who had abstained for nearly a year said she was careful about kissing due to expectations that may arise: "Might as well just keep it to a minimum...they feel like once they've got in kissing they could do more and make you want to change your mind about it [sex]." However, an inability to avoid situations with sexual possibility or implement safeguards within situations created difficulty in practicing secondary abstinence.

\section{Discussion}

Experiences shared by sexually experienced African-American young women interested in becoming or remaining abstinent provided insight about the dissonance between interest in and the practice of secondary abstinence. The most salient barriers were those related to relationships with their partners. Similar to research on condom use [13]-[15], fear of a negative response from their partner and potential loss of the relationship made it difficult to practice abstinence. Barriers unique to abstinence included financial dependence on a sexual partner and being in situations that provided greater opportunity for sex.

Findings from this study suggest that empowering African-American young women by teaching knowledge and skills for developing healthier relationships with partners may play an important role in reducing disparities in STI/HIV. This type of approach is consistent with the Centers for Disease Control and other public health organizations' new initiatives that promote sexual health by placing greater emphasis on the development of healthy relationships, the context in which an individual's behavior occurs [24]. Thus, addressing relationship barriers that contribute to power imbalances that favor the male partner and limit sexual decision-making power for young women, as well as equipping them to set and enforce behavioral and environmental boundaries, could facilitate implementation of sexual health choices that are consistent with one's desire to abstain.

More specifically, some of our findings may be useful in strengthening the abstinence component of interventions in the following ways:

First, a sexually active young woman may in fact experience negative reactions from a partner who wants to have a sexual relationship with her. Therefore, young women may benefit from learning healthy strategies to cope with negative reactions from partners. For example, cognitive restructuring can help individuals process negative thoughts and emotions in a more productive way. Additionally, efforts to promote abstinence may benefit from exploring perceptions about male sexuality and sexual behavior. Anticipating a negative response from their male partner was rooted in a widely accepted view that sex is the main priority in men's lives and the aim of relationships with women. Similar to interventions that include activities that challenge the accuracy of images of women, it may also be beneficial to address stereotypes about male sexuality, such as hypersexualized 
images of males portrayed in music and other media that can impact how women (and men) view and understand male sexuality.

Further, a barrier unique to sexually experienced young women should be targeted as well. Some face an expectation for sex after initiating sex with a male partner, at least for the duration of the relationship, or after the formal relationship ends in some instances. Therefore, correcting misperceptions that one is obligated to continue having sex after it is introduced into a relationship could prove valuable when intervening with sexually experienced young women.

Next, since having little or no sexual decision making power can be detrimental it is essential for young women to be able to identify power imbalances, including more subtle ones, and be equipped with skills that can facilitate a shift in power toward equality. For example, intervention activities may focus on helping young women recognize characteristics of healthy and unhealthy relationships, including an assessment of the distribution of power. Young women may also benefit from assertive communication skills training for example.

In addition, the majority of the respondents referred to sexual situations as a major hindrance to being abstinent. Individuals with successful attempts to abstain described strategies for avoiding or limiting time spent alone or boundaries they created to prevent them from progressing to sex. Thus, another way to enhance the abstinence component of interventions could be teaching young women how to avoid sexual situations or navigate situations should they find themselves in one.

Potential limitations of this study should be acknowledged. First, although the PI's role as a member of the intervention study staff aided recruitment and rapport-building, young women's responses may have been impacted by social desirability bias. Second, although steps were taken to increase validity, such as transcribing audio recordings verbatim and conducting a validity check of the codebook with an independent researcher, the potential for bias cannot be completely eliminated. Finally, as with any qualitative investigation, the findings from this study may not extend beyond the study sample. However, barriers identified in this study could be examined quantitatively to determine whether they are relevant for other African-American females and possibly other populations.

Promoting the development of healthier relationships among young women may be a vital mechanism for sexual health promotion. Sexually experienced young women who choose abstinence, whether alone or in combination with other STI/HIV prevention strategies, should be fully equipped to follow through with their personal sexual health choices. In doing so, researchers and health professionals may take another step toward reducing STIs and HIV among this population. Importantly, promoting the development of healthier relationships among young women and their intimate partners has the possibility to not only positively impact sexual health , but also improve overall physical and mental health as well and to set the foundation for developing generally healthy relationships with others in various domains of their lives.

\section{References}

[1] Centers for Disease Control and Prevention (2014) HIV/AIDS among African Americans. http://www.cdc.gov/hiv/risk/racialethnic/aa/facts/index.html

[2] Centers for Disease Control and Prevention (2009) Sexually Transmitted Diseases in the United States, 2008. National Surveillance Data for Chlamydia, Gonorrhea and Syphilis. http://www.cdc.gov/std/stats08/trends.htm

[3] Crepaz, N., Marshall, K. J., Aupont, L.W., Jacobs, E.D., Mizuno, Y., Kay, L. S., Jones, P., McCree, D.H. and O’Leary, A. (2009) The Efficacy of HIV/STI Behavioral Interventions for AfricanAmerican Females in the United States: A Meta-Analysis. American Journal of Public Health, 99, 2069-2078. http://dx.doi.org/10.2105/AJPH.2008.139519

[4] DiClemente, R.J. and Wingood, G.M. (1995) A Randomized Controlled Trial of an HIV Sexual Risk Reduction Intervention for Young African-American Women. Journal of the American Medical Association, 274, 1271-1276. http://dx.doi.org/10.1001/jama.1995.03530160023028

[5] DiClemente, R.J., Wingood, G.M., Harrington, K.F., Lang, D.L., Davies, S.L., Hook, E.W. Oh, M.K., Crosby, R.A., Hertzberg, V.S., Gordon, A.B., Hardin, J.W., Parker, S. and Robillard, A. (2004) Efficacy of an HIV Prevention Intervention for African American Adolescent Girls: A Randomized Controlled Trial. Journal of the American Medical Association, 292, 171-179. http://dx.doi.org/10.1001/jama.292.2.171

[6] DiClemente, R.J., Wingood, G.M., Rose, E. S., Sales, J.M., Lang, D.L., Calliendo, A.M., Hardin, J. and Crosby, R.A. (2009) Efficacy of a Sexually Transmitted Disease/Human Immunodeficiency Virus Sexual Risk-Reduction Intervention for African-American Adolescent Females Seeking Sexual Health Services. Archives of Pediatric \& Adolescent Medicine, 63, 1112-1121. 
[7] Sterk, C.E., Theall, K.P. and Elifson, K.W. (2003) Effectiveness of a Risk Reduction Intervention among African-American Women Who Use Crack Cocaine. AIDS Education and Prevention, 15, 15-32. http://dx.doi.org/10.1521/aeap.15.1.15.23843

[8] Jemmott, L.S., Jemmott, J.B. and O’Leary, A. (2007) Effects on Sexual Risk Behavior and STD Rate of Brief HIV/ STD Prevention Interventions for African American Women in Primary Settings. American Journal of Public Health, 97, 1-7. http://dx.doi.org/10.2105/AJPH.2003.020271

[9] AED Center on AIDS and Community Health (2009) Diffusion of Effective Behavioral Interventions Project. http://www.effectiveinterventions.org/en/home.aspx

[10] DiClemente, R.J., Salazar, L.F. and Crosby, R.A. (2007) A Review of STD/HIV Preventive Interventions for Adolescents: Sustaining Effects Using an Ecological Approach. Journal of Pediatric Psychology, 32, 888-906. http://dx.doi.org/10.1093/jpepsy/jsm056

[11] Henrich, C.C., Brookmeyer, K.A., Shrier, L.A. and Shahar, G. (2006) Supportive Relationships and Sexual Risk Behavior in Adolescence: An Ecological-Transactional Approach. Journal of Pediatric Psychology, 31, 286-297. http://dx.doi.org/10.1093/jpepsy/jsj024

[12] Small, S.A. and Luster, T. (1994) Adolescent Sexual Activity: An Ecological, Risk-Factor Approach. Journal of Marriage \& Family, 56, 181-192. http://dx.doi.org/10.2307/352712

[13] Crosby, R.A., DiClemente, R.J., Wingood, G.M., Salazar, L.F., Head, S., Rose, E., and Sales, J.M. (2008) Sexual Agency versus Relational Factors: A Study of Condom Use Antecedents among High-Risk Young African American Women. Sexual Health, 5, 41-47. http://dx.doi.org/10.1071/SH07046

[14] Bowleg, L., Lucas, K.J. and Tschann, J.M. (2004) The Ball Was Always in His Court: An Exploratory Analysis of Relationship Scripts, Sexual Scripts, and Condom Use among African-American Women. Psychology of Women Quarterly, 28, 70-82. http://dx.doi.org/10.1111/j.1471-6402.2004.00124.X

[15] Small, E., Weinman, M.L., Buzi, R.S and Smith, P.B. (2010) Explaining Condom Use Disparity among Black and Hispanic Female Adolescents. Child and Adolescent Social Work Journal, 27, 365-376. http://dx.doi.org/10.1007/s10560-010-0207-8

[16] Frye, V., Williams, K., Bond, K.T., Henny, K., Cupid, M., Weiss, L., Lucy, D. and Koblin, B.A. (2012) Condom Use and Concurrent Partnering among Heterosexually Active African American Men: A Qualitative Report. Journal of Urban Health, 90, 953-969. http://dx.doi.org/10.1007/s11524-012-9747-x

[17] Noar, S.M., Webb, E., Stee, S.V., Feist-Price, S., Crosby, R.A., Willoughby, J.F. and Troutman, A. (2012) Sexual Partnerships, Risk Behaviors, and Condom Use among Low-Income Heterosexual African-Americans: A Qualitative Study. Archives of Sexual Behavior, 41, 959-970. http://dx.doi.org/10.1007/s10508-011-9890-6

[18] Bradley, E., Sales, J.M., Murray, C.C. and DiClemente, R.J. (2012) Examining Interest in Secondary Abstinence among Young African-American Females at Risk for HIV/STIs. Health Education Research, 27, 1120-1128. http://dx.doi.org/10.1093/her/cys068

[19] Rasberry, C.N. and Goodson, P. (2009). Predictors of Secondary Abstinence in US. College Undergraduates. Archives of Sexual Behavior, 38, 74-86. http://dx.doi.org/10.1007/s10508-007-9214-z

[20] Haglund, K. (2006). Understanding Sexual Abstinence in African-American Teens. American Journal of Maternal \& Child Nursing, 31, 86-92. http://dx.doi.org/10.1097/00005721-200603000-00006

[21] Glaser, B.G. and Strauss, A. (1967) The Discovery of Grounded Theory: Strategies for Qualitative Research. Aldine Publishing, Chicago.

[22] Strauss, A. and Corbin, J. (1998) Basics of Qualitative Research: Techniques and Procedures for Developing Grounded Theory. 2nd Edition, Sage Publications, Thousand Oaks.

[23] Charmaz, K. (2006) Constructing Grounded Theory: A Practical Guide through Qualitative Analysis. Sage Publications, Thousand Oaks.

[24] Tharp, A.T., Carter, M., Fasula, A.M., Hatfield-Timajchy, K., Jayne, P.E., Latzman, N.E. and Kinsey, J. (2013) Advancing Adolescent Sexual and Reproductive Health by Promoting Healthy Relationships. Journal of Women's Health, 22, 911-914. http://dx.doi.org/10.1089/jwh.2013.4534 
Scientific Research Publishing (SCIRP) is one of the largest Open Access journal publishers. It is currently publishing more than 200 open access, online, peer-reviewed journals covering a wide range of academic disciplines. SCIRP serves the worldwide academic communities and contributes to the progress and application of science with its publication.

Other selected journals from SCIRP are listed as below. Submit your manuscript to us via either submit@scirp.org or Online Submission Portal.
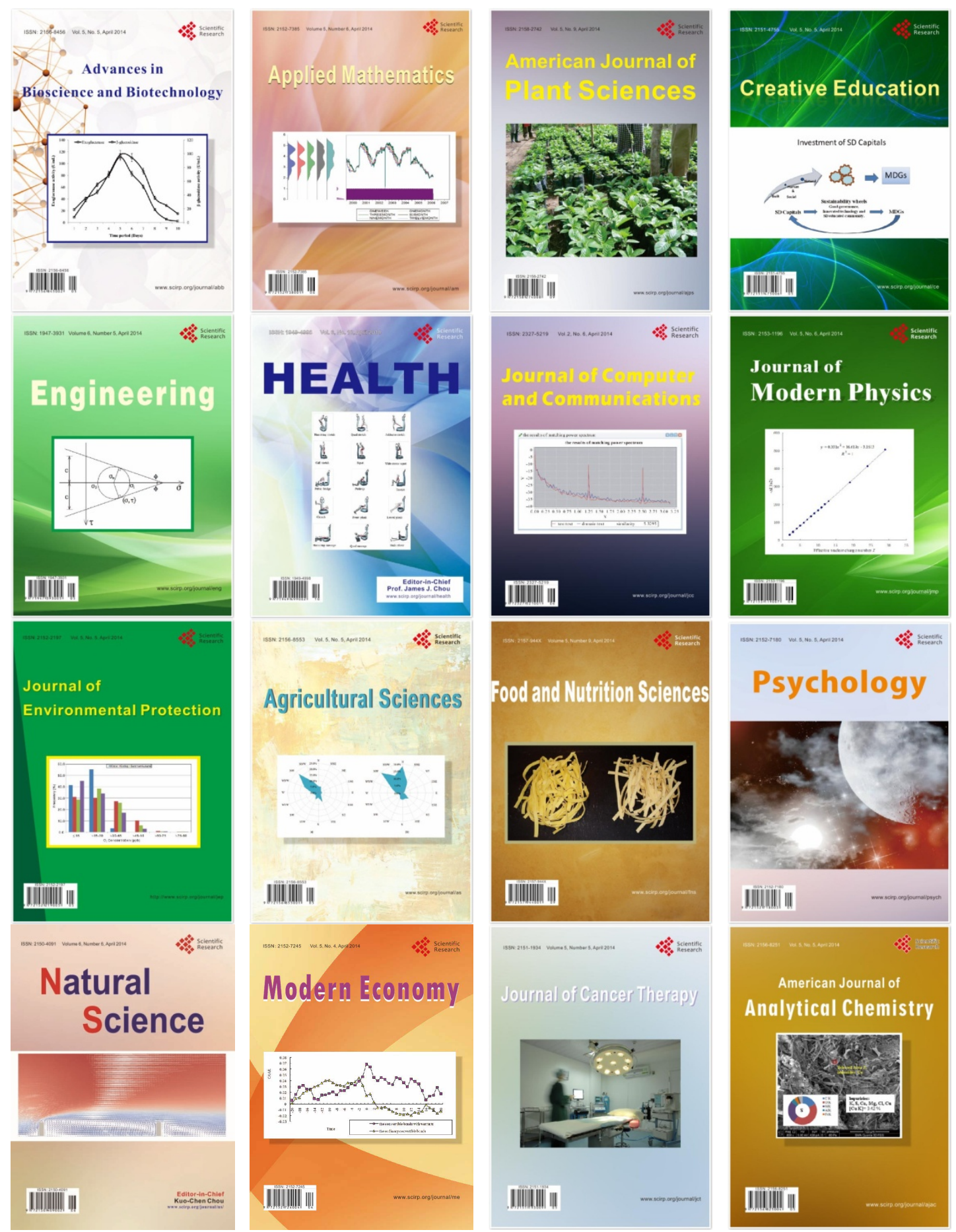